\title{
Physiological and Pathophysiological Roles of Hydrogen Sulfide in the Gastrointestinal Tract
}

\author{
John L. Wallace
}

\begin{abstract}
Like nitric oxide and carbon monoxide, hydrogen sulfide has historically been recognized as an industrial pollutant, but in recent years, it has been shown to be an important mediator of many physiological processes. Hydrogen sulfide contributes to the maintenance of gastrointestinal mucosal defense and repair. It also exerts many antiinflammatory effects, including inhibition of leukocyte adherence to the vascular endothelium and leukocyte migration to sites of inflammation. Conversely, inhibition of endogenous hydrogen sulfide synthesis leads to a loss of mucosal integrity and to an increase in mucosal inflammation. Hydrogen sulfide therefore appears to have overlapping actions with nitric oxide and prostaglandins in terms of modulating mucosal defense and resolution of inflammation. Recent evidence suggests that these properties of hydrogen sulfide can be exploited in the design of novel therapies for ulcerative and inflammatory diseases of the gastrointestinal tract. Antioxid. Redox Signal. 12, 1125-1133.
\end{abstract}

\section{Introduction}

I $\mathrm{N}$ RECENT YEARS, the potential role played by endogenous hydrogen sulfide $\left(\mathrm{H}_{2} \mathrm{~S}\right)$ in several physiological and pathophysiological processes has become better appreciated, despite the paucity of highly selective inhibitors of $\mathrm{H}_{2} \mathrm{~S}$ synthesis $(15,56)$. This article is focused on the role of $\mathrm{H}_{2} \mathrm{~S}$ in the regulation of inflammation and healing in the digestive system, as well as on the potential of exploiting $\mathrm{H}_{2} \mathrm{~S}$ in novel therapies. Another gaseous mediator, nitric oxide (NO), was previously thought of primarily as an industrial pollutant (like $\mathrm{H}_{2} \mathrm{~S}$ ). It has similarly been shown to be an important mediator of many physiological processes and has been exploited in drug design $(44,50)$.

In this article, the roles of $\mathrm{H}_{2} \mathrm{~S}$ in modulating inflammation are discussed, as is the role of this mediator in maintaining mucosal integrity and in promoting the healing of injury. In each case, the effects of novel $\mathrm{H}_{2} \mathrm{~S}$ donors in relevant animal models are reviewed. These studies suggest important roles for $\mathrm{H}_{2} \mathrm{~S}$ in mediating mucosal defense, particularly in the stomach, in regulating inflammatory processes, and in promoting the resolution of inflammation and injury. $\mathrm{H}_{2} \mathrm{~S}$ releasing derivatives of nonsteroidal antiinflammatory drugs (NSAIDs) have been shown to be more effective than the parent NSAIDs but to cause markedly less gastric injury. An $\mathrm{H}_{2} \mathrm{~S}$-releasing derivative of mesalamine has been shown to be significantly more effective than the parent drug in rodent models of colitis. These $\mathrm{H}_{2} \mathrm{~S}$-releasing antiinflammatory drugs suppress leukocyte extravasation and expression of several proinflammatory mediators, including tumor necrosis factor- $\alpha$ (TNF- $\alpha)$, interleukin-1 (IL-1), and interferon- $\gamma$ (IFN- $\gamma)$.

\section{Modulation of Inflammation}

\section{Leukocyte function}

Several lines of evidence point to an important role of $\mathrm{H}_{2} \mathrm{~S}$ in regulating some of the key events in the inflammatory cascade and in the resolution of inflammation. These actions of $\mathrm{H}_{2} \mathrm{~S}$ (and of nitric oxide) contribute to the ability of these gaseous mediators to enhance gastrointestinal mucosal resistance to injury. The induction of adhesive interactions between circulating leukocytes and the vascular endothelium is the initial step in the process of extravasation of leukocytes and their migration to sites of injury or infection. An important role of $\mathrm{H}_{2} \mathrm{~S}$ as a tonic regulator of this process was suggested by the observation that inhibition of $\mathrm{H}_{2} \mathrm{~S}$ synthesis in rats resulted in a rapid increase in leukocyte adherence in mesenteric venules (60). When $\mathrm{H}_{2} \mathrm{~S}$ synthesis is inhibited, an increase in expression of adhesion molecules on the endothelium (P-selectin, ICAM-1) and on leukocytes (LFA-1) can be detected (14). Leukocyte adherence stimulated either by aspirin or by a formylated tripeptide (fMLP) could be dosedependently inhibited by exogenous $\mathrm{H}_{2} \mathrm{~S}$ (i.e., through administration of an $\mathrm{H}_{2} \mathrm{~S}$ donor). $\mathrm{H}_{2} \mathrm{~S}$ donors also were effective

Farncombe Family Institute for Digestive Health Research, McMaster University, Hamilton, Ontario, Canada. 
in reducing leukocyte accumulation in a rat airpouch model in which inflammation was induced by injection of carrageenan (60). Conversely, administration of an inhibitor of endogenous $\mathrm{H}_{2} \mathrm{~S}$ synthesis (BCA) significantly enhanced carrageenaninduced leukocyte infiltration (60). Modulation of leukocyte extravasation by $\mathrm{H}_{2} \mathrm{~S}$ also was demonstrated in a rat model of endotoxin-induced lung and liver inflammation (25).

Altered leukocyte interactions with the endothelium also were observed in mice genetically deficient of one of the key enzymes for $\mathrm{H}_{2} \mathrm{~S}$ synthesis (CBS). Mice completely deficient in this enzyme did not survive, but those that were heterozygous for CBS exhibited increased vascular permeability, reduced leukocyte-rolling velocity, and increased leukocyte adherence to the vascular endothelium (21).

Resolution of an inflammatory process is complex, involving the removal of infiltrating leukocytes and the repair of tissue injury (39). Several groups of mediators have been identified that play key roles in the resolution of inflammation, and $\mathrm{H}_{2} \mathrm{~S}$ appears to be one such mediator. Its role in promoting the resolution of gastrointestinal injury and inflammation is discussed later. One of the mechanisms through which $\mathrm{H}_{2} \mathrm{~S}$ may contribute to resolution of inflammation is by inducing neutrophils to undergo apoptosis (29), a necessary precursor to their engulfment by macrophages (39).

The vasodilator action of $\mathrm{H}_{2} \mathrm{~S}$ has been suggested to occur, at least in part, through activation of ATP-sensitive $\mathrm{K}^{+}$ channels $\left(\mathrm{K}_{\mathrm{ATP}}^{+}\right)$. Some of the antiinflammatory actions of $\mathrm{H}_{2} \mathrm{~S}$ also may be mediated through activation of $\mathrm{K}_{\mathrm{ATP}}^{+}$channels. Thus, the inhibitor effects of $\mathrm{H}_{2} \mathrm{~S}$ donors on leukocyte adherence stimulated by aspirin were blocked by glibenclamide, an antagonist of $\mathrm{K}_{\mathrm{ATP}}^{+}$channels (14).

The observation that administration of an inhibitor of endogenous $\mathrm{H}_{2} \mathrm{~S}$ synthesis resulted in significant adhesion of leukocytes (primarily neutrophils) to the vascular endothelium in mesenteric venules of rats (60) suggested that $\mathrm{H}_{2} \mathrm{~S}$ tonically downregulates leukocyte adhesion and emigration. Recent studies in the rat provide evidence that supports this hypothesis. Treatment of rats twice daily for a week with $\beta$-cyano-alanine (BCA), a reversible inhibitor of CSE, resulted in a significant increase in myeloperoxidase activity in the colon (51). Myeloperoxidase is an enzyme found in cells of myeloid origin and, in particularly high concentrations, in neutrophils. It has been used extensively as a biochemical marker of neutrophil infiltration (8). Similar results were obtained in rats treated with an inhibitor of CBS [O-(carboxymethyl) hydroxylamine hemihydrochloride] (51).

Iodoacetamide is an agent frequently used to induce inflammation in the gastrointestinal tract. When given orally, it induces gastritis (4), whereas intracolonic administration results in the development of colitis (41). These effects have been ascribed to the ability of iodoacetamide to reduce mucosal levels of sulfhydryls, such as glutathione. However, iodoacetamide binds covalently to cysteine, thereby limiting its availability for conversion to $\mathrm{H}_{2} \mathrm{~S}$. Iodoacetamide has been used as an inhibitor of $\mathrm{H}_{2} \mathrm{~S}$ synthesis (5). Given the observations described earlier with respect to elevated mucosal myeloperoxidase levels (i.e., increased leukocyte infiltration) after inhibition of $\mathrm{H}_{2} \mathrm{~S}$ synthesis, it is possible that the mucosal inflammation induced by iodoacetamide is also a response to diminished mucosal $\mathrm{H}_{2} \mathrm{~S}$ synthesis. Interestingly, suppression of $\mathrm{H}_{2} \mathrm{~S}$ synthesis by iodoacetamide may result in a compensatory increase in the expression of CSE. We observed that

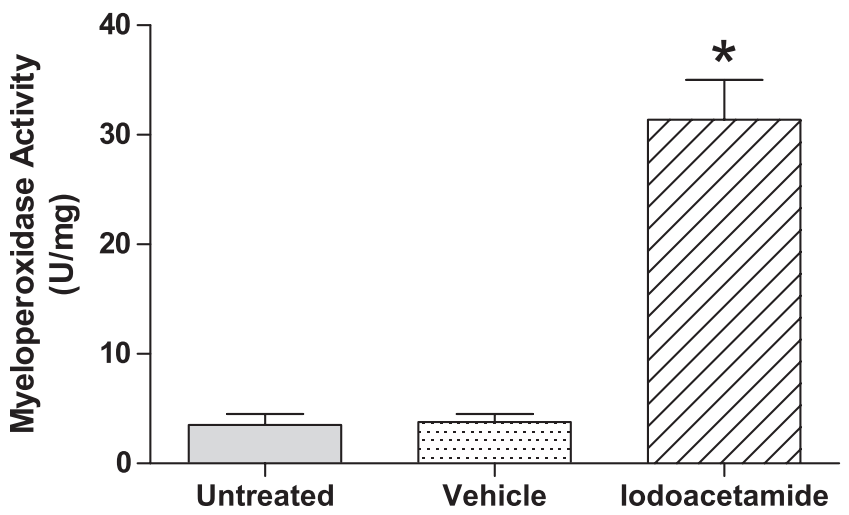

FIG. 1. Oral administration of iodoacetamide, an inhibitor of hydrogen sulfide synthesis, induces inflammation in the stomach. Myeloperoxidase activity was measured in samples of the stomach, as an index of granulocyte infiltration ( ${ }^{*} p<0.05$ versus the other two groups). Oral administration of iodoacetamide (versus vehicle) was performed daily for 5 days (as described in ref. 4). ${ }^{*} p<0.05$ versus the other two groups.

treatment of rats for 5 days with iodoacetamide resulted in substantial mucosal inflammation (Fig. 1), as had been observed previously (4). When the ability of the mucosa to generate $\mathrm{H}_{2} \mathrm{~S}$ from exogenous L-cysteine was examined, a substantial increase was observed as compared with that in healthy controls, and this could be suppressed by an inhibitor of CSE (Fig. 2). Of course, it is possible that this increase in the capacity of the mucosal tissue to generate $\mathrm{H}_{2} \mathrm{~S}$ (from exogenous substrate) was a consequence of the inflammatory process, as opposed to being specifically related to the sequestration of endogenous cysteine by iodoacetamide.

\section{Edema formation}

Plasma exudation is a hallmark feature of inflammation that also appears to be modulated by $\mathrm{H}_{2} \mathrm{~S}$, although conflict-

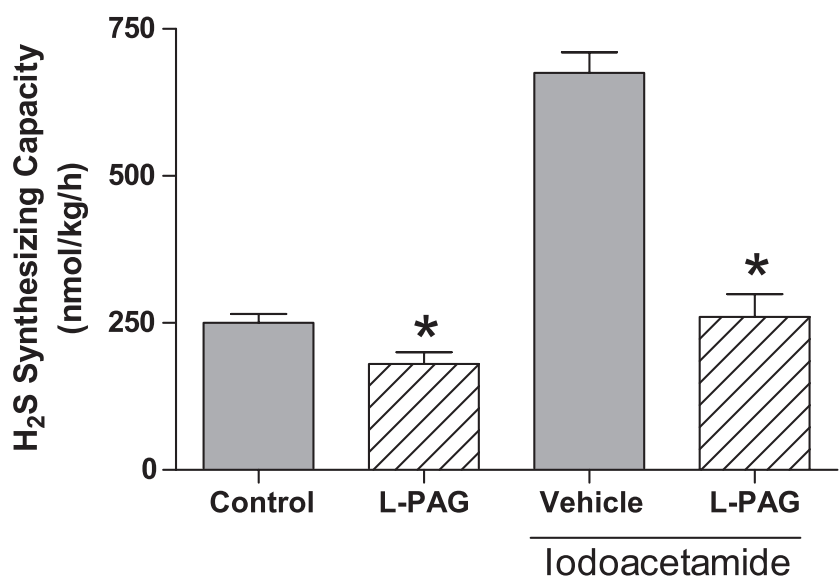

FIG. 2. Oral administration of iodoacetamide, an inhibitor of hydrogen sulfide synthesis, increases the capacity of the tissue to produce $\mathrm{H}_{2} \mathrm{~S}$ from exogenous L-cysteine. Oral administration of iodoacetamide (or vehicle) was performed daily for 5 days (as described in ref. 4). ${ }^{*} p<0.05$ versus the corresponding control/vehicle group. (Iodoacetamide administration was carried out as described in ref. 4). 
ing results have been reported in this regard. For example, intraperitoneal administration of $\mathrm{H}_{2} \mathrm{~S}$ donors significantly and dose-dependently reduced paw edema induced by intraplantar injection of carrageenan (54). These effects of $\mathrm{H}_{2} \mathrm{~S}$ appeared to be mediated through activation of $\mathrm{K}_{\mathrm{ATP}}^{+}$channels, as the antiedema effects of $\mathrm{H}_{2} \mathrm{~S}$ donors were inhibited by glibenclamide and mimicked by pinacidil (an activator of $\mathrm{K}_{\mathrm{ATP}}^{+}$channels) (60). Interestingly, carrageenan-induced paw edema was exacerbated by BCA, an inhibitor of $\mathrm{H}_{2} \mathrm{~S}$ synthesis, consistent with the hypothesis that $\mathrm{H}_{2} \mathrm{~S}$ tonically downregulates inflammation. In studies by two separate laboratories, oral administration of an $\mathrm{H}_{2} \mathrm{~S}$-releasing diclofenac derivative also was found to reduce carrageenan-induced paw edema in the rat, significantly more potently than did diclofenac $(40,46)$.

In contrast to these studies, Bhatia et al. (7) reported that injection of carrageenan into the footpad of rats resulted in a significant increase in the capacity of the tissue to convert L-cysteine to $\mathrm{H}_{2} \mathrm{~S}$ (in vitro). When an inhibitor of CSE (propargylglycine; PAG) was given to the rats, they observed a decrease in paw edema, suggesting that endogenous $\mathrm{H}_{2} \mathrm{~S}$ acted to promote edema formation. This inhibitor also suppressed the paw-tissue myeloperoxidase activity, an index of granulocyte infiltration. However, as the authors suggest, by inhibiting $\mathrm{H}_{2} \mathrm{~S}$ synthesis, PAG would likely reduce blood flow to the paw, and this could contribute to the observed reduction in edema and granulocyte infiltration.

\section{Visceral pain}

Distrutti et al. (12) used the colorectal distention model in rats to assess the potential role of $\mathrm{H}_{2} \mathrm{~S}$ as a modulator of visceral sensation. Rats were treated with vehicle and then subjected to graded distentions of a balloon catheter inserted into the distal colon of the rat. After a recovery period, the experiment was repeated, but the rats were treated with an $\mathrm{H}_{2} \mathrm{~S}$ donor (NaHS), L-cysteine, or vehicle (the observer recording the abdominal-withdrawal responses, which are indicative of visceral pain, was blind as to the treatments the rats received). The $\mathrm{H}_{2} \mathrm{~S}$ donor and L-cysteine significantly reduced the pain responses to colorectal distention, and the effects of these agents was blocked by pretreatment with glibenclamide, suggesting that the effects of $\mathrm{H}_{2} \mathrm{~S}$ were produced through the activation of $\mathrm{K}_{\mathrm{ATP}}^{+}$channels. Moreover, an agonist of $\mathrm{K}_{\mathrm{ATP}}^{+}$ channels, pinacidil, mimicked the analgesic effects of $\mathrm{H}_{2} \mathrm{~S}$. The $\mathrm{H}_{2} \mathrm{~S}$ donor and L-cysteine also significantly reduced the increase in spinal cFos expression associated with colorectal distention, providing further evidence for an antinociceptive effect of $\mathrm{H}_{2} \mathrm{~S}$. Although at higher concentrations, NaHS was able to increase colonic compliance, consistent with previous reports that $\mathrm{H}_{2} \mathrm{~S}$ can relax intestinal smooth muscle $(18,43$, $61)$, lower doses of NaHS produced a significant reduction of visceral pain without affecting compliance.

A more marked antinociceptive effect of $\mathrm{H}_{2} \mathrm{~S}$ was observed when experiments similar to those described earlier were performed in rats that were recovering from a bout of colitis induced by trinitrobenzene sulfonic acid (12). Such studies are relevant to the human conditions of inflammatory bowel disease and irritable bowel syndrome, in which patients experience severe pain and an increased sensitivity to colorectal distention (6). In the rat model, allodynia (i.e., perception of pain from a stimulus that is usually not perceived as painful) was observed in the rats with colitis, and enhanced hyperalgesia occurred, as compared with that observed in healthy rats (Fig. 3). Treatment with NaHS produced a reversal of the allodynia and a marked reduction of hyperalgesia.

Distrutti et al. (11) provided further evidence for a role of $\mathrm{H}_{2} \mathrm{~S}$ in modulating visceral pain in a study in which a novel drug in development for the treatment of inflammatory bowel disease was tested. Mesalamine (5-aminosalicylic acid) is the first-line therapy for mild-to-moderate colitis and Crohn disease, but it is a weak drug, with doses of up to $6 \mathrm{~g} /$ day being required to induce remission. ATB- 429 is $\mathrm{H}_{2} \mathrm{~S}$-releasing derivative of mesalamine, which has been shown to be significantly more effective in accelerating resolution of colitis in mouse and rat models (16). In the colorectal distention model, both with healthy rats and with rats recovering from a bout of colitis, treatment with ATB-429 produced a significantly greater effect than did mesalamine in terms of reducing visceral pain perception.

$\mathrm{H}_{2} \mathrm{~S}$ has been reported to activate transient receptor potential vanilloid-1 (TRPV1), which might be expected to be pronociceptive rather than antinociceptive. Matsunami et al. (31) recently reported pronociceptive effects of intracolonic administration of 0.5 and 5 nmoles of NaHS to mice, but no effect of lower or higher concentrations. Unfortunately, no other $\mathrm{H}_{2} \mathrm{~S}$ donor was studied. The pronociceptive effects of

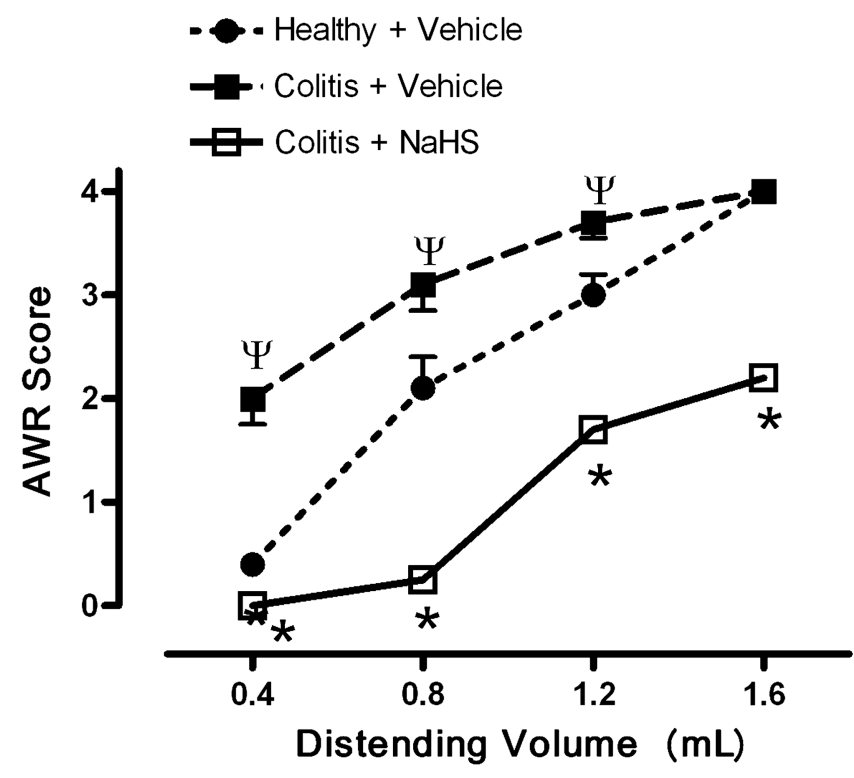

FIG. 3. Visceral analgesic effects of a hydrogen sulfide donor (NaHS) in rats recovering from colitis. Data from Distrutti et al. (12). Distention of the colon results in a progressive increase in the severity of abdominal withdrawal responses (AWR) in healthy rats, and these responses are significantly increased in rats examined 2 weeks after induction of colitis ( ${ }^{\Psi} p<0.05$ versus the corresponding data in the healthy rats). Note that at the lowest level of distention, which does not induce a significant AWR in healthy rats, a substantial AWR occurs in the rats with colitis (allodynia). Intraperitoneal pretreatment with the hydrogen sulfide donor abolishes the allodynia and also significantly reduces the hyperalgesia exhibited in rats with colitis that were treated only with vehicle $\left({ }^{*} p<0.05\right.$ compared with the corresponding data from rats with colitis treated with vehicle). 
NaHS were not due to actions on $\mathrm{K}_{\mathrm{ATP}}^{+}$channels, but were blocked by a T-type calcium channel blocker.

Some of the issues relevant to the controversy regarding $\mathrm{H}_{2} \mathrm{~S}$ as a pro- versus antinociceptive in the GI tract were recently reviewed (37). Evidence suggests that $\mathrm{H}_{2} \mathrm{~S}$ can be proor antinociceptive, or neither, in tissues other than those of the GI tract $(1,10)$, and it seems likely that the particular effect produced by an $\mathrm{H}_{2} \mathrm{~S}$ donor is context-specific and may also be variable with the concentration of $\mathrm{H}_{2} \mathrm{~S}$ that is generated and the kinetics of release of $\mathrm{H}_{2} \mathrm{~S}$.

\section{Proinflammatory mediator expression}

Considerable evidence exists from both in vitro and in vivo studies that $\mathrm{H}_{2} \mathrm{~S}$ can modulate the expression of a number of other inflammatory mediators, and this may contribute to the modulation of inflammation and injury by $\mathrm{H}_{2} \mathrm{~S}$. Oh et al. (33) observed that $\mathrm{H}_{2} \mathrm{~S}$ inhibited endotoxin-induced iNOS expression and NO production in cultured macrophages, and further demonstrated that this was a consequence of inhibition of the activation of the transcription factor NF- $\kappa$ B. An inhibitory effect of $\mathrm{H}_{2} \mathrm{~S}$ on endotoxin-induced upregulation of iNOS expression, NO production, and TNF- $\alpha$ expression was similarly observed in cultured microglia (20) (Table 1). At least some of these effects appeared to be due to inhibition of p38 MAP kinase phosphorylation (20). Effects on $\mathrm{H}_{2} \mathrm{~S}$ on p38 MAP kinase also were reported in studies of neutrophils (35). $\mathrm{H}_{2} \mathrm{~S}$ also dose-dependently reduced heme oxygenase-1 expression, through an ERK-dependent mechanism (33). Although not directly studied, an effect on heme oxygenase expression could affect the production of another gaseous mediator, carbon monoxide.

Modulation of proinflammatory mediator expression also was demonstrated in several in vivo models, including models of GI injury and inflammation. For example, mucosal expression of mRNA for iNOS, the chemokine RANTES, and several proinflammatory cytokines (TNF- $\alpha$, IFN- $\gamma$, IL-1, IL-2, IL-12 p40) was markedly upregulated in a mouse model of colitis (16). Expression of each of the aforementioned was significantly reduced in mice that had been treated for several days with ATB-429, an $\mathrm{H}_{2} \mathrm{~S}$-releasing derivative of mesalamine. In contrast, neither ATB-429 nor mesalamine reduced expression of the antiinflammatory cytokine, IL-10 (16). Similarly, $\mathrm{H}_{2} \mathrm{~S}$ donors (given intracolonically) reduced TNF- $\alpha$ mRNA and protein levels in the colon in a rat model of colitis, in association with a significant reduction in the severity of the colitis (51). In an in vitro organ-culture study of colonic tissue from patients with ulcerative colitis, Bai et al. (3) demonstrated that diallyl trisulfide, which releases $\mathrm{H}_{2} \mathrm{~S}$, decreased TNF- $\alpha$ expression.

As discussed in more detail later, the modulation of proinflammatory mediator expression also can be observed in models of NSAID-induced gastric injury. NSAIDs trigger an upregulation of TNF- $\alpha$ expression in the gastric mucosa of rats $(2,14,36)$. When $\mathrm{H}_{2} \mathrm{~S}$ donors were administered before the NSAIDs, the upregulation of TNF- $\alpha$ expression was inhibited (14). An $\mathrm{H}_{2} \mathrm{~S}$-releasing NSAID derivative did not trigger the increase in expression of TNF- $\alpha$ in the gastric mucosa that was observed when the parent NSAID was administered (46). Moreover, the $\mathrm{H}_{2} \mathrm{~S}$-releasing NSAID inhibited endotoxininduced NF- $\kappa \mathrm{B}$ activation and the accompanying increase in plasma TNF- $\alpha$ and nitrate/nitrite (25). Interestingly, and consistent with observations in experimental colitis (16), this compound augmented the increase in plasma IL-10 that was induced by endotoxin (25).

\section{Resistance to Injury}

The resistance of the GI mucosa to injury induced by luminal agents, including endogenous [acid, bile, digestive enzymes] and exogenous [ethanol, nonsteroidal antiinflammatory drugs (NSAIDs)] is dependent on a complex network of factors collectively referred to as "mucosal defense" (55). Mucosal defense is modulated by a number of soluble mediators, most notably, prostaglandins and nitric oxide. Recent studies suggest that $\mathrm{H}_{2} \mathrm{~S}$ can be added to this list of mediators that contribute significantly to mucosal defense. Moreover, as has been accomplished with prostaglandins and $\mathrm{NO}$, it may be possible to exploit the GI-protective effects of $\mathrm{H}_{2} \mathrm{~S}$ in the development of novel therapeutic agents.

NSAIDs are among the major causes of GI ulceration and bleeding. The damaging effects of NSAIDs in the GI tract, particularly in the stomach, are directly linked to their ability to inhibit mucosal prostaglandin synthesis (55). Suppression of prostaglandin synthesis impairs mucosal defense (reduced blood flow, reduced bicarbonate secretion), results in TNF- $\alpha$ release, and triggers adherence of leukocytes (primarily neutrophils) to the vascular endothelium in the GI microcirculation (55). This latter event is critical in the development of erosions in the stomach (52). Blockade of NSAID-induced leukocyte adherence by immune-depleting circulating neutrophils (48), by administration of antibodies directed against key adhesion molecules $(45,49)$, or by co-administration of NO (54) prevented damage developing in the stomach. These observations provided the basis for the development of NOreleasing NSAIDs, also called "COX-inhibiting nitric oxide donors" $(44,50)$. Given that $\mathrm{H}_{2} \mathrm{~S}$ shares with $\mathrm{NO}$ the ability to suppress leukocyte adherence, including that induced by aspirin $(60)$, and, like NO, is a vasodilator $(14,56)$, we hypothesized that $\mathrm{H}_{2} \mathrm{~S}$ may also play an important role in mucosal defense and may be able to prevent NSAID-induced gastric damage (53). We observed that suppression of endogenous $\mathrm{H}_{2} \mathrm{~S}$ synthesis increased the susceptibility to NSAID-induced gastric damage in the rat (14). $\mathrm{H}_{2} \mathrm{~S}$ donors, conversely, reduced the severity of NSAID-induce damage. Figure 4 shows the effects of allyl disulfide, a garlic-derived $\mathrm{H}_{2} \mathrm{~S}$ donor, on gastric damage in the rat induced by oral administration of naproxen. $\mathrm{H}_{2} \mathrm{~S}$ donors also were shown to prevent NSAIDinduced decreases in gastric blood flow and the increase in leukocyte adherence (14). The latter was likely attributable to the observed reduction in the expression of key adhesion molecules (LFA-1, ICAM-1), as well as a significant reduction in NSAID-induced TNF- $\alpha$ synthesis (14).

Based on the observations that concomitant administration of an $\mathrm{H}_{2} \mathrm{~S}$ donor and an NSAID largely abrogated the gastricdamaging effects of the latter, attempts have been made to develop NSAID derivatives that liberate $\mathrm{H}_{2} \mathrm{~S}$ in vivo. Thus, $\mathrm{H}_{2}$ S-releasing derivatives of diclofenac (ATB-337) and indomethacin were shown to spare the gastric mucosa of the rat from damage, even though they suppressed gastric prostaglandin synthesis to the same extent as did the parent drug $(46,53)$. ATB-337 also produced markedly less intestinal damage and bleeding (i.e., reduced the decrease in hematocrit) as compared with diclofenac. In terms of antiinflammatory activity, ATB-337 (which is also referred to as 


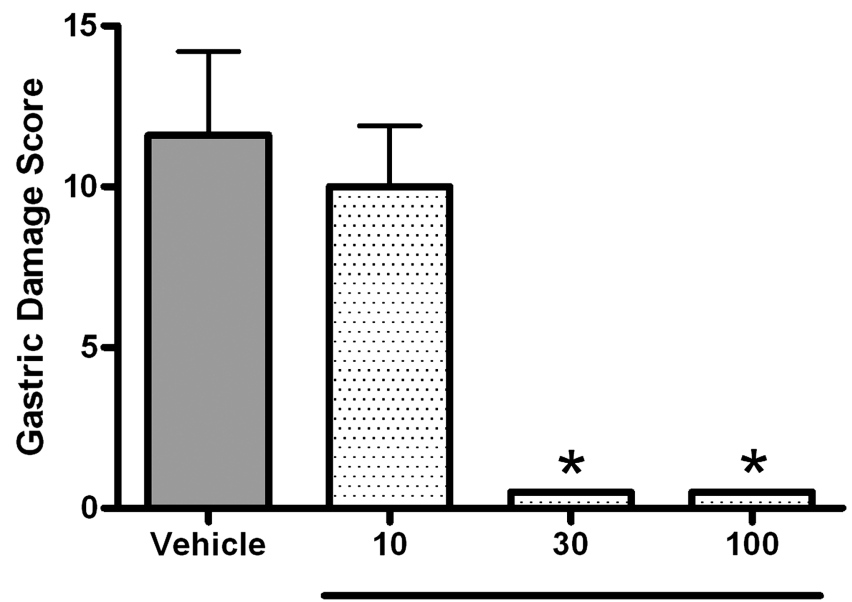

Allyl Disulfide ( $\mu \mathrm{mol} / \mathrm{kg})$

FIG. 4. Allyl disulfide, an $\mathrm{H}_{2} \mathrm{~S}$-generating substance derived from garlic, dose-dependently reduced the severity of naproxen-induced gastric hemorrhagic damage in the rat stomach. Groups of five rats each were treated with allyl disulfide or vehicle $30 \mathrm{~min}$ before oral administration of naproxen $(10 \mathrm{mg} / \mathrm{kg})$. The rats were killed $3 \mathrm{~h}$ later, and the extent of gastric damage was blindly scored as described in reference 41 . Allyl disulfide did not interfere with the ability of naproxen to inhibit gastric prostaglandin $\mathrm{E}_{2}$ synthesis. ${ }^{*} p<0.05$ versus the vehicle-treated group.

"S-diclofenac" in some publications; 25) exhibits somewhat better effects than equimolar doses of diclofenac. For example, ATB-337 was more effective in reducing edema than was the parent drug $(25,46)$.

The ability of the $\mathrm{H}_{2} \mathrm{~S}$-releasing NSAID to spare the gastric mucosa from injury despite suppression of mucosal prostaglandin synthesis may be attributable to the suppression of leukocyte adherence by this agent. ATB-337 did not stimulate leukocyte adherence, as was observed with diclofenac, and did not cause the elevation of expression of LFA-1 or ICAM-1 that was observed with diclofenac (46). This effect of the $\mathrm{H}_{2} \mathrm{~S}-$ releasing NSAID derivative also was evident in the studies of Li et al. (25), who observed a significant reduction of LPSinduced accumulation of neutrophils in the lung and liver in animals treated with $S$-diclofenac.

\section{Resolution of Injury and Inflammation}

\section{Gastric ulcer healing}

Gastric and duodenal ulceration has decreased in incidence markedly since the discovery that most such ulcers are associated with Helicobacter pylori infection. However, NSAIDinduced ulcers remain a clinical concern, particularly in patients requiring antiinflammatory therapy. NSAIDs interfere with the healing of ulcers, most likely related to suppression of COX-2-derived prostaglandin synthesis (55). Previous studies demonstrated key roles for endogenous NO in healing of experimental gastric ulcers in rodents $(13,24,27)$. Given the similar actions of $\mathrm{NO}$ and $\mathrm{H}_{2} \mathrm{~S}$ with respect to mucosal defense, we explored the possibility that $\mathrm{H}_{2} \mathrm{~S}$ may influence gastric ulcer healing in a rat model. Ulcers were induced by brief serosal application of acetic acid (13). Over the 2- to 3-day period after this treatment, an ulcer forms on the mucosal surface of the stomach and penetrates into the submucosal layer. NSAIDs and selective COX-2 inhibitors have been shown to significantly delay ulcer healing in this model $(13,28)$, consistent with what occurs in humans.

Two of the key enzymes for $\mathrm{H}_{2} \mathrm{~S}$ synthesis (CSE and CBS) were significantly upregulated at both 3 and 6 days after serosal application of acetic acid (47). In parallel, a marked upregulation of $\mathrm{H}_{2} \mathrm{~S}$ synthesis by gastric tissue was found. When rats with ulcers were treated twice daily with vehicle for 7 days, the ulcers healed to about half the size they were before treatment. However, if the rats were treated with an $\mathrm{H}_{2} \mathrm{~S}$ donor (Lawesson's Reagent or 4-hydroxybutyrate) in the same manner, a significant enhancement of ulcer healing was observed $(30 \mu \mathrm{mol} / \mathrm{kg}$ produced this effect, but $10 \mu \mathrm{mol} / \mathrm{kg}$ did not) (Fig. 5). Combined treatment with an $\mathrm{H}_{2} \mathrm{~S}$ donor (Lawesson's Reagent) and an NO donor (glyceryltrinitrate) produced greater healing that was seen with either of these donors alone, but no synergistic effect was evident. Interestingly, treatment with the $\mathrm{K}_{\mathrm{ATP}}^{+}$agonist, pinacidil, or the $\mathrm{K}_{\text {ATP }}^{+}$antagonist, glibenclamide, did not affect ulcer healing, suggesting that actions on this channel were not responsible for the beneficial effects of $\mathrm{H}_{2} \mathrm{~S}$ (47).

Ulcer healing also was significantly enhanced, in a dosedependent manner, by twice-daily administration of L-cysteine (47). Significant effects of L-cysteine on healing were observed with a dose that had no effect on gastric-tissue glutathione levels. Administration of an inhibitor of CSE significantly impaired ulcer healing and blocked L-cysteine-induced enhancement of ulcer healing. This provides evidence that the beneficial effects of L-cysteine on ulcer healing were indeed related to its metabolism to liberate $\mathrm{H}_{2} \mathrm{~S}$.

As mentioned earlier, the ability of NSAIDs to delay healing of ulcers is a significant clinical concern. With the rat ulcer



FIG. 5. Hydrogen sulfide promotes healing of gastric ulcers in rats. Gastric ulcers were induced by application of acetic acid to the serosal surface of the stomach (as described in reference 47). Three days later, the mean ulcer area was $\sim 75 \mathrm{~mm}^{2}$ (Day 3). In rats treated twice daily with vehicle for the following 4 days, the ulcers had healed to approximately half that size. Treatment over the same period of time with Lawesson's Reagent (LR), an $\mathrm{H}_{2} \mathrm{~S}$ donor, significantly enhanced ulcer healing. Treatment with mesalamine (Mesal; 5-aminosalicylic acid) did not significantly affect ulcer healing as compared with that in the vehicle-treated group, but treatment with an $\mathrm{H}_{2} \mathrm{~S}$-releasing mesalamine derivative (ATB-429) significantly enhanced ulcer healing. ${ }^{*} p<0.05$ versus the day 3 group. ${ }^{\alpha} p<0.05$ versus the vehicle-treated group. 
Table 1. Mechanisms of Antinnflammatory ACTIONS OF $\mathrm{H}_{2} \mathrm{~S}$

\begin{tabular}{ll}
\hline Mechanism & References \\
\hline Inhibition of activation of NF- $\kappa \mathrm{B}$ & 25,33 \\
Inhibition of heme oxygenase-1 expression & 33 \\
Inhibition of activation of p38 MAP kinase & 20,35 \\
Elevation of intracellular cAMP & 23 \\
Antioxidant activity & 22 \\
Scavenging of peroxynitrite & 57 \\
Activation of $\mathrm{K}_{\text {ATP }}^{+}$ & 42,56 \\
Inhibition of caspase-3 cleavage & 35 \\
Inhibition of hypochlorous acid activity & 58 \\
\hline
\end{tabular}

This is a list of some of the possible mechanisms through which hydrogen sulfide can exert antiinflammatory actions.

model, experiments were performed to determine whether co-administration of an $\mathrm{H}_{2} \mathrm{~S}$ donor with an NSAID would abrogate any detrimental effect of the NSAID on ulcer healing (47). Twice-daily treatment of rats with diclofenac, a commonly used NSAID, resulted in a significant impairment of ulcer healing (i.e., significant healing was not observed, as compared with rats treated with vehicle) (Table 2). However, in rats co-treated with diclofenac and Lawesson's Reagent, healing of ulcers was restored.

The mechanism of action of $\mathrm{H}_{2} \mathrm{~S}$ in promoting the healing of ulcers is not clear. Suppression of gastric acid secretion can result in more rapid ulcer healing, but the $\mathrm{H}_{2} \mathrm{~S}$ donors were found to have no effect on intragastric $\mathrm{pH}$ or on volume of gastric acid secreted. It is possible that the $\mathrm{H}_{2} \mathrm{~S}$ donors promoted angiogenesis in the ulcer bed, which could contribute to ulcer healing, but this has not been investigated. $\mathrm{H}_{2} \mathrm{~S}$ has been shown to promote angiogenesis (9).

\section{Colitis}

Ulcerative colitis and Crohn disease are serious chronic conditions associated with severe pain, diarrhea, and bleeding. Treatment of these diseases is a significant challenge and is only modestly effective, except in the mildest cases. Several inflammatory mediators, cytokines, and chemokines have

Table 2. Possible Mechanisms of the GI-Protective EFFECT OF $\mathrm{H}_{2} \mathrm{~S}$

\begin{tabular}{ll}
\hline Mechanism & References \\
\hline Increased mucosal blood flow & 14 \\
Increased epithelial secretion & 38 \\
Activation of $\mathrm{K}_{\text {ATP channels }}^{+}$ & 14 \\
Reduction of leukocyte & $1,14,25,60$ \\
$\quad$ adhesion/infiltration & $14,16,25,51$ \\
Reduction of TNF- $\alpha / \mathrm{IL}-1 \beta / \mathrm{IFN}-\gamma$ & 19 \\
$\quad$ expression & 34,38 \\
Metabolic fuel for epithelial cells & \\
$\quad$ aftivation of capsaicin-sensitive & $22,57,58$ \\
\hline Antioxidant effects &
\end{tabular}

This is a list of some of the possible mechanisms through which hydrogen sulfide can increase the resistance of the gastrointestinal mucosa to injury. In some cases, the mechanism has been demonstrated only in nongastrointestinal cells or tissues.

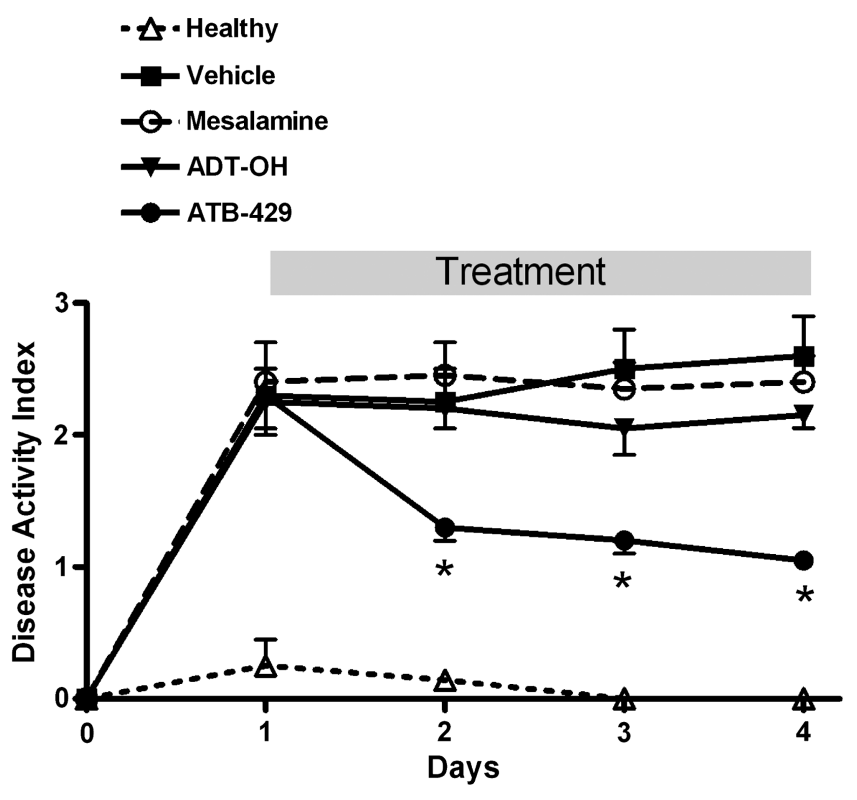

FIG. 6. A hydrogen sulfide-releasing derivative of mesalamine (ATB-429) is more effective in promoting the resolution of colitis in mice than an equimolar dose of mesalamine $(50 \mathrm{mg} / \mathrm{kg}$ twice daily, $\mathrm{PO})$ or the hydrogen sulfide-releasing moiety alone (ADT-OH). Colitis was induced by intracolonic trinitrobenzene sulfonic acid on day 0 in all groups except "healthy." Treatment with the test drugs was initiated after measurement of the disease activity on day 1 . Disease activity is a composite score for weight loss, diarrhea, and rectal bleeding (see ref. 16). ${ }^{*} p<0.05$ versus the other groups.

been implicated in the pathogenesis of colitis. Of these, TNF- $\alpha$ has been the best exploited from a therapeutic standpoint, through the use of monoclonal antibodies directed against this cytokine. However, these therapies are expensive and are not without risk. The most commonly used medication for treatment of colitis is mesalamine (5-aminosalicylic acid), which is effective in inducing remission in mild-to-moderate cases.

Given the observations that $\mathrm{H}_{2} \mathrm{~S}$ can attenuate some elements of inflammation (leukocyte adherence, edema formation, etc.) and can accelerate healing of injured GI tissue, we explored the possible role of this mediator in a rat model of colitis. Intracolonic administration of trinitrobenzene sulfonic acid (TNBS) results in severe colitis bearing a histologic similarity to Crohn disease (32). Within a few hours, a marked increase in $\mathrm{H}_{2} \mathrm{~S}$ synthesis can be detected, which increases further (to $\sim 100$-fold over levels in the normal colon) in parallel with increased infiltration of granulocytes into the damaged tissue (51). Over the weeks that follow, the severity of the colitis diminishes, and in parallel, a decrease in colonic $\mathrm{H}_{2} \mathrm{~S}$ synthesis is observed. The colonic $\mathrm{H}_{2} \mathrm{~S}$ synthesis could be inhibited by $>70-95 \%$ by co-incubation of the colonic tissue with inhibitors of CSE and CBS (51).

Whether the elevated $\mathrm{H}_{2} \mathrm{~S}$ synthesis by the inflamed colon contributes to the tissue injury or to the resolution of that injury was investigated by treating rats with a number of inhibitors of $\mathrm{H}_{2} \mathrm{~S}$ synthesis (51), including an inhibitor of CBS $(\mathrm{CHH})$, a reversible inhibitor of CSE (BCA), and an irrevers- 
ible inhibitor of CSE (PAG). Twice-daily treatment with these inhibitors resulted in significant mortality, with deaths occurring fastest with the CBS inhibitor, and the least with the reversible inhibitor of CSE. In the rats that survived treatment with BCA, a marked exacerbation of the severity of colitis was observed. Treatment of healthy rats with the same inhibitors also resulted in significant mortality, particularly with the CBS inhibitor. In surviving rats, treatment with the CSE and CBS inhibitors resulted in atrophy in the intestine and a significant increase in tissue myeloperoxidase activity (indicative of elevated granulocyte infiltration). Thus, these results suggest that $\mathrm{H}_{2} \mathrm{~S}$ produced in the context of colitis is exerting a predominantly beneficial effect (inhibition of its synthesis leads to exacerbated colitis). Moreover, in healthy animals, $\mathrm{H}_{2} \mathrm{~S}$ synthesis appears to act as a tonic downregulator of granulocyte infiltration into intestinal tissue.

These conclusions were further supported by studies of $\mathrm{H}_{2} \mathrm{~S}$ donors. Twice-daily treatment of colitic rats, by enema, with Lawesson's Reagent or with NaHS resulted in a significant attenuation of the severity of colitis (51). Moreover, a significant reduction of expression of TNF- $\alpha$ was observed in the rats treated with the $\mathrm{H}_{2} \mathrm{~S}$ donors. Moreover, studies of an $\mathrm{H}_{2} \mathrm{~S}$-releasing derivative of mesalamine (ATB-429) further supported the notion that $\mathrm{H}_{2} \mathrm{~S}$ exerts beneficial effects in the context of colitis. In TNBS-induced colitis in mice, treatment twice daily for a week with ATB-429 resulted in significantly more-rapid resolution of colitis than did treatment with mesalamine (16) (Fig. 6). ATB-429 also was more potent than mesalamine. Although mesalamine had little or no effect on colonic expression of TNF- $\alpha$, IL- $1 \beta$, and IFN- $\gamma$, treatment with ATB-429 resulted in significant inhibition of expression of each of these proinflammatory cytokines. As well as reducing the severity of inflammation, ATB-429 was shown to accelerate mucosal healing. When tested in the acetic acid-induced gastric ulcer model, described earlier, ATB-429 significantly enhanced healing as compared with vehicle or with an equimolar dose of mesalamine (47) (Fig. 6).

\section{Future Perspectives}

Over the past decade, our knowledge of the physiological and pathophysiological roles of $\mathrm{H}_{2} \mathrm{~S}$ has grown considerably, and this is true for studies of the digestive system as much as for any other system in the body. As was the case in the early 1990s with respect to studies of NO, efforts to understand better the importance of $\mathrm{H}_{2} \mathrm{~S}$ are limited by the paucity of highly selective pharmacologic and molecular tools. As such tools are developed, and this is already occurring with respect to $\mathrm{H}_{2} \mathrm{~S}$ donors, investigators will be able to acquire a better understanding of the roles of this molecule in various processes. With more-selective inhibitors and with better systems for measuring $\mathrm{H}_{2} \mathrm{~S}$ production in vivo, some of the controversies regarding the effects of $\mathrm{H}_{2} \mathrm{~S}$ (such as whether it is anti- or pronociceptive) may be resolved. Whereas studies of cardiovascular function have been performed in mice genetically deficient in either CSE or CBS $(21,59)$, no studies have been published to date on the GI phenotypes of these mice.

Many unanswered questions remain regarding $\mathrm{H}_{2} \mathrm{~S}$ synthesis and catabolism in the digestive system. Although more is being learned about the enzyme systems responsible for $\mathrm{H}_{2} \mathrm{~S}$ production $(17,26,30)$, little is known regarding the specific cellular sources of this mediator. It also is not clear to what extent luminal bacteria contribute to the production of $\mathrm{H}_{2} \mathrm{~S}$ from samples of intestine.

The development of $\mathrm{H}_{2} \mathrm{~S}$-releasing antiinflammatory drugs appears to be a promising approach to the exploitation of the potent and broad effects of this molecule, at least based on preclinical studies that have been published. $\mathrm{H}_{2} \mathrm{~S}$ exerts actions in the digestive system that are very similar to those of $\mathrm{NO}$ and, to some extent, prostaglandins. Thus, administration of $\mathrm{H}_{2} \mathrm{~S}$ donors may be of particular benefit in circumstances in which production of one or both of these other "mucosalprotective" mediators is impaired.

\section{Acknowledgments}

Dr. Wallace holds the Farncombe Family Chair in Digestive Health Research at McMaster University, and his research is supported by grants from the Canadian Institutes of Health Research, the Crohn's and Colitis Foundation of Canada, and the Ontario Premier's Summit Award.

\section{Author Disclosure Statement}

Dr. Wallace holds shares in Antibe Therapeutics, Inc., and Ginova Pharm, Ltd., companies that are developing hydrogen-sulfide-releasing drugs for various indications.

\section{References}

1. Andruski B, McCafferty DM, Ignacy T, Millen B, and McDougall JJ. Leukocyte trafficking and pain behavioural responses to a hydrogen sulfide donor in acute monoarthritis. Am J Physiol 295: R814-R820, 2008.

2. Appleyard CB, McCafferty DM, Tigley AW, Swain MG, and Wallace JL. Tumor necrosis factor mediation of NSAIDinduced gastric damage: role of leukocyte adherence. Am J Physiol 270: G42-G48, 1996.

3. Bai AP, Ouyang Q, and $\mathrm{Hu}$ W. Diallyl trisuldife inhibits tumour necrosis factor- $\alpha$ expression in inflamed mucosa of ulcerative colitis. Dig Dis Sci 50: 1426-1431, 2005.

4. Barnett K, Bell CJ, McKnight W, Dicay M, Sharkey KA, and Wallace JL. Role of cyclooxygenase- 2 in modulating gastric acid secretion in the normal and inflamed rat stomach. Am J Physiol 279: G1292-G1297, 2000.

5. Benavides GA, Squadrito GL, Mills RW, Patel HD, Isbell TS, Patel RP, Darley-Usmar VM, Doeller JE, and Kraus DW. Hydrogen sulfide mediates the vasoactivity of garlic. Proc Natl Acad Sci U S A 104: 17977-17982, 2007.

6. Bernstein $\mathrm{CN}$, Niazi N, Robert M, Mertz H, Kodner A, Munakata J, Naliboff B, and Mayer EA. Rectal afferent function in patients with inflammatory and functional intestinal disorders. Pain 66: 151-161, 1996.

7. Bhatia M, Sidhapuriwala J, Moochhala SM, and Moore PK. Hydrogen sulphide is a mediator of carrageenan-induced hindpaw oedema in the rat. Br J Pharmacol 145: 141-144, 2005.

8. Boughton-Smith NK, Wallace JL, and Whittle BJR. Relationship between arachidonic acid metabolism, myeloperoxidase activity and leukocyte infiltration in a rat model of inflammatory bowel disease. Agents Actions 25: 115-123, 1988.

9. Cai WJ, Wang MJ, Moore PK, Jin HM, Yao T, and Zhu YC. The novel proangiogenic effect of hydrogen sulfide is dependent on Akt phosphorylation. Cardiovasc Res 76: 29-40, 2007.

10. Cunha TM, Dal-Secco D, Verri WA, Guerrero AT, Souza GR, Vieira SM, Lotufo CM, Neto AF, Ferreira SH, and Cunha FQ. 
Dual role of hydrogen sulfide in mechanical inflammatory hypernociception. Eur J Pharmacol 20: 127-135, 2008.

11. Distrutti E, Sediari L, Mencarelli A, Renga B, Orlandi S, Russo G, Caliendo G, Santagada V, Cirino G, Wallace JL, and Fiorucci S. 5-Amino-2-hydroxybenzoic acid 4-(5-thioxo$5 \mathrm{H}-[1,2]$ dithiol-3yl)-phenyl ester (ATB-429), a hydrogen sulfide-releasing derivative of mesalamine, exerts antinociceptive effects in a model of postinflammatory hypersensitivity. J Pharmacol Exp Ther 319: 447-458, 2006.

12. Distrutti E. Sediari L, Mencarelli A, Renga B, Orlandi S, Antonelli E, Roviezzo F, Morelli A, Cirino G, Wallace JL, and Fiorucci S. Evidence that hydrogen sulfide exerts antinociceptive effects in the gastrointestinal tract by activating $\mathrm{K}_{\text {AтP }}$ channels. J Pharmacol Exp Ther 316: 325-335, 2006.

13. Elliott SN, McKnight W, Cirino G, and Wallace JL. A nitric oxide-releasing nonsteroidal anti-inflammatory drug accelerates gastric ulcer healing in rats. Gastroenterology 109: 524 530, 1995.

14. Fiorucci S, Antonelli E, Distrutti E, Rizzo G, Mencarelli A, Orlandi S, Zanardo R, Renga B, Di Sante M, Morelli A, Cirino G, and Wallace JL. Inhibition of hydrogen sulfide generation contributes to gastric injury caused by antiinflammatory nonsteroidal drugs. Gastroenterology 129: 1210-1224, 2005.

15. Fiorucci S, Distrutti E, Cirino G, and Wallace JL. The emerging roles of hydrogen sulfide in the gastrointestinal tract and liver. Gastroenterology 131: 259-271, 2006.

16. Fiorucci S, Orlandi S, Mencarelli A, Caliendo G, Santagada V, Distrutti E, Santucci L, Cirino G, and Wallace JL. Enhanced activity of a hydrogen sulfide-releasing derivative of mesalamine (ATB-429) in a mouse model of colitis. $\mathrm{Br} J$ Pharmacol 150: 996-1002, 2007.

17. Furne J, Springfield J, Koenig T, DeMaster E, and Levitt MD. Oxidation of hydrogen sulfide and methanethiol to thiosulfate by rat tissues: a specialized function of the colonic mucosa. Biochem Pharmacol 62: 255-259, 2001.

18. Gallego D, Clavé P, Donovan J, Rahmati R, Grundy D, Jiménez M, and Beyak MJ. The gaseous mediator, hydrogen sulphide, inhibits in vitro motor patterns in the human, rat and mouse colon and jejunum. Neurogastroenterol Motil 20: 1306-1316, 2008.

19. Goubern M, Andriamihaja M, Nübel T, Blachier F, and Bouillaud F. Sulfide, the first inorganic substrate for human cells. FASEB J 21: 1699-1706, 2007.

20. Hu LF, Wong PT, Moore PK, and Bian JS. Hydrogen sulfide attenuates lipopolysaccharide-induced inflammation by inhibition of p38 mitogen-activated protein kinase in microglia. J Neurochem 100: 1121-1128, 2007.

21. Kamath AF, Chauhan AK, Kisucka J, Dole VS, Loscalzo J, Handy DE, and Wagner DD. (2006) Elevated levels of homocysteine compromise blood-brain barrier integrity in mice. Blood 107: 591-593, 2006.

22. Kashiba M, Kajimura M, Goda N, and Suematsu M. From $\mathrm{O}_{2}$ to $\mathrm{H}_{2} \mathrm{~S}$ : a landscape view of gas biology. Keio J Med 51: 1-10, 2002.

23. Kimura $H$. Hydrogen sulfide induces cyclic AMP and modulates the NMDA receptor. Biochem Biophys Res Commun 267: 129-133, 2000.

24. Konturek SJ, Brzozowski T, Majka J, Pytko-Polonczyk J, and Stachura J. Inhibition of nitric oxide synthase delays healing of chronic gastric ulcers. Eur J Pharmacol 239: 215217,1993

25. Li L, Rossoni G, Sparatore A, Lee LC, Del Soldato P, and Moore PK. Anti-inflammatory and gastrointestinal effects of a novel diclofenac derivative. Free Radic Biol Med 42: 706$719,2007$.

26. Linden DR, Sha L, Mazzone A, Stoltz GJ, Bernard CE, Furne JK, Levitt MD, Farrugia G, and Szurszewski JH. Production of the gaseous signal molecule hydrogen sulfide in mouse tissues. J Neurochem 106: 1577-1585, 2008.

27. Ma L and Wallace JL. Endothelial nitric oxide synthase modulates gastric ulcer healing in rats. Am J Physiol Gastrointest Liver Physiol 279: G341-G346, 2000.

28. Ma L, del Soldato P, and Wallace JL. Divergent effects of new cyclooxygenase inhibitors on gastric ulcer healing: shifting the angiogenic balance. Proc Natl Acad Sci U S A 99: 13243-13237, 2002.

29. Mariggiò MA, Minunno V, Riccardi S, Santacroce R, De Rinaldis P, and Fumarulo R. Sulfide enhancement of PMN apoptosis. Immunopharmacol Immunotoxicol 20: 399-408, 1998.

30. Martin GR, McKnight GW, Dicay MS, Coffin CS, Ferraz JG, and Wallace JL. Hydrogen sulphide synthesis in the rat and mouse gastrointestinal tract. Dig Liver Dis 42: 103-109, 2009.

31. Matsunami M, Tarui T, Mitani K, Nagasawa K, Fukushima O, Okubo K, Yoshida S, Takemura M, and Kawabata A. Luminal hydrogen sulfide plays a pronociceptive role in mouse colon. Gut 58: 751-761, 2009.

32. Morris GP, Beck PL, Herridge MS, Depew WT, Szewczuk MR, Wallace JL. Hapten-induced model of chronic inflammation and ulceration in the rat colon. Gastroenterology 96: 795-803, 1989.

33. Oh G-S, Pae HO, Lee BS Kim BN, Kim JM, Kim HR, Jeon SB, Jeon WK, Chae HJ, and Chung HT. Hydrogen sulfide inhibits nitric oxide production and nuclear factor- $\kappa \mathrm{B}$ via heme oxygenase-1 expression in RAW264.7 macrophages stimulated with lipopolysaccharide. Free Radic Biol Med 41: 106-119, 2006.

34. Patacchini R, Santicioli P, Giuliani S, and Maggi CA. Hydrogen sulfide $\left(\mathrm{H}_{2} \mathrm{~S}\right)$ stimulates capsaicin-sensitive primary afferent neurons in the rat urinary bladder. $\mathrm{Br} J$ Pharmacol 142: 31-41, 2004.

35. Rinaldi L, Gobbi G, Pambianco M, Micheloni C, Mirandola $\mathrm{P}$, and Vitale M. Hydrogen sulfide prevents apoptosis of human PMN via inhibition of p38 and caspase 3. Lab Invest 86: 391-397, 2006.

36. Santucci L, Fiorucci S, Di Matteo FM, and Morelli A. Role of tumor necrosis factor alpha release and leukocyte margination in indomethacin-induced gastric injury in rats. Gastroenterology 108: 393-401, 1995.

37. Schemann M and Grundy D. Role of hydrogen sulfide in visceral nociception. Gut 58: 744-747, 2009.

38. Schicho R, Krueger D, Zeller F,Von Weyhern CWH, Frieling T, Kimura H, Ishii I, Di Giorgio R, Campi B, and Schemann $\mathrm{M}$. Hydrogen sulfide is a novel prosecretory neuromodulator in the guinea-pig and human colon. Gastroenterology 131: 1542-1552, 2006

39. Serhan CN, Brain SD, Buckley CD, Gilroy DW, Haslett C, O'Neill LA, Perretti M, Rossi AG, and Wallace JL. Resolution of inflammation: state of the art, definitions and terms. FASEB J 21: 325-332, 2007.

40. Sidhapuriwala J, Li L, Sparatore A, Bhatia M, and Moore PK. Effect of S-diclofenac, a novel hydrogen sulfide releasing derivative, on carrageenan-induced hindpaw oedema formation in the rat. Eur J Pharmacol 569: 149-154, 2007.

41. Szabo H, Sato F, Takami K, Szabo S. New ulcerative colitis model induced by sulfhydryl blockers in rats and the effects of antiinflammatory drugs on the colitis. Jpn J Pharmacol 73: 299-309, 1997. 
42. Tang G, Wu L, Liang $\mathrm{W}$, and Wang R. Direct stimulation of $\mathrm{K}_{\mathrm{ATP}}$ channels by exogenous and endogenous hydrogen sulfide in vascular smooth muscle cells. Mol Pharmacol 68: 1757-1764, 2005.

43. Teague B, Asiedu S, and Moore PK. The smooth muscle relaxant effect of hydrogen sulphide in vitro: evidence for a physiological role to control intestinal contractility. $\mathrm{Br} J$ Pharmacol 137: 139-145, 2002.

44. Wallace JL and Del Soldato P. The therapeutic potential of NO-NSAIDs. Fund Clin Pharmacol 17: 11-20, 2003.

45. Wallace JL, Arfors K-E, and McKnight GW. A monoclonal antibody against the CD18 leukocyte adhesion molecule prevents indomethacin-induced gastric damage in the rabbit. Gastroenterology 100: 878-883, 1991.

46. Wallace JL, Caliendo G, Santagada V, Cirino G, and Fiorucci S. Gastrointestinal safety and anti-inflammatory effects of a hydrogen sulfide-releasing diclofenac derivative in the rat. Gastroenterology 132: 261-271, 2007.

47. Wallace JL, Dicay M, McKnight W, and Martin GR. Hydrogen sulfide modulates gastric ulcer healing in rats. FASEB J 21: 4070-4076, 2007.

48. Wallace JL, Keenan CM, and Granger DN. Gastric ulceration induced by nonsteroidal anti-inflammatory drugs is a neutrophil-dependent process. Am J Physiol 259: G462-G467, 1990.

49. Wallace JL, McKnight GW, Miyasaka M, Tamatani T, Pauson J, Anderson DC, Granger DN, and Kubes P. Role of endothelial adhesion molecules in NSAID-induced gastric mucosal injury. Am J Physiol 265: G993-G998, 1993.

50. Wallace JL, Viappiani S, and Bolla M. Cyclooxygenaseinhibiting nitric oxide donators for osteoarthritis. Trends Pharmacol Sci 30: 112-117, 2009.

51. Wallace JL, Vong L, McKnight W, Dicay M, and Martin G. Endogenous and exogenous hydrogen sulfide promotes resolution of colitis in rats. Gastroenterology 137: 569-578, 2009.

52. Wallace JL. Gastric ulceration: critical events at the neutrophil endothelium interface. Can J Physiol Pharmacol 71: 98102, 1993.

53. Wallace JL. Hydrogen sulfide-releasing anti-inflammatory drugs. Trends Pharmacol Sci 28: 501-505, 2007.

54. Wallace JL. Mechanisms of nonsteroidal anti-inflammatory drug (NSAID) induced gastrointestinal damage: potential for development of gastrointestinal tract safe NSAIDs. Can J Physiol Pharmacol 72: 1493-1498, 1994.

55. Wallace JL. Prostaglandins, NSAIDs, and gastric mucosal protection: why doesn't the stomach digest itself? Physiol Rev 88: 1547-1565, 2008.

56. Wang R. Two's company, three's a crowd: can $\mathrm{H}_{2} \mathrm{~S}$ be the third endogenous gaseous transmitter? FASEB J 16: 17921798,2002

57. Whiteman M, Armstrong JS, Chu SH, Jia-Ling S, Wong BS, Cheung NS, Halliwell B, and Moore PK. The novel neuro- modulator hydrogen sulfide: an endogenous peroxynitrite 'scavenger'? J Neurochem 90: 765-768, 2004.

58. Whiteman M, Cheung NS, Zhu YZ, Chu SH, Siau JL, Wong BS, Armstrong JS, and Moore PK. Hydrogen sulphide: a novel inhibitor of hypochlorous acid-mediated oxidative damage in the brain? Biochem Biophys Res Commun 326: 794798, 2005.

59. Yang G, Wu L, Jiang B, Yang W, Qi J, Cao K, Meng Q, Mustafa AK, Mu W, Zhang S, Snyder SH, and Wang R. $\mathrm{H}_{2} \mathrm{~S}$ as a physiologic vasorelaxant: hypertension in mice with deletion of cystathionine gamma-lyase. Science 322: 587-590, 2008.

60. Zanardo RC, Brancaleone V, Distrutti E, Fiorucci S, Cirino G, and Wallace JL. Hydrogen sulfide is an endogenous modulator of leukocyte-mediated inflammation. FASEB J 20: 2118-2120, 2006.

61. Zhao W, Zhang J, Lu Y, and Wang R. The vasorelaxant effect of $\mathrm{H}_{2} \mathrm{~S}$ as a novel endogenous gaseous $\mathrm{K}_{\mathrm{ATP}}$ channel opener. EMBO J 20: 6008-6016, 2001.

Address correspondence to: Dr. John L. Wallace Department of Medicine, HSC-3N9 McMaster University 1200 Main Street West Hamilton, Ontario L8N $3 Z 5$ Canada

E-mail: jwalla@mcmaster.ca

Date of first submission to ARS Central, September 16, 2009; date of acceptance, September 19, 2009.

$$
\begin{aligned}
& \text { Abbreviations Used } \\
\mathrm{AWR} & =\text { abdominal withdrawal response } \\
\mathrm{BCA} & =\beta \text {-cyanoalanine } \\
\mathrm{CBS} & =\text { cystathionine } \beta \text {-synthase } \\
\mathrm{CSE} & =\text { cystathionine } \gamma \text {-lyase } \\
\mathrm{ERK} & =\text { extracellular signal-regulated kinase } \\
\mathrm{GI} & =\text { gastrointestinal } \\
\mathrm{H}_{2} \mathrm{~S} & =\text { hydrogen sulfide } \\
\mathrm{IFN} & =\text { interferon } \\
\mathrm{IL} & =\text { interleukin } \\
\mathrm{iNOS} & =\text { inducible nitric oxide synthase } \\
\mathrm{MAP} & =\text { mitogen-activated protein kinase } \\
\mathrm{NO} & =\text { nitric oxide } \\
\mathrm{NSAID} & =\text { nonsteroidal antiinflammatory drug } \\
\mathrm{PAG} & =\text { propargylglycine } \\
\mathrm{PG} & =\text { prostaglandin } \\
\mathrm{TNF} & =\text { tumor necrosis factor }
\end{aligned}
$$


